\title{
Pensando a fotografia como fonte histórica
}

\author{
Marli Brito M. Albuquerque* \\ ("Pesquisadoras da Casa de Oswal- \\ Lisabel Espellet Klein* \\ do Cruz)
}

$O$ presente artigo procura levantar algumas

questôes que consideramos pertinentes para quem se propōe a trabalhar com fotografias, como fonte histórica.

Para tanto, sugere possiveis "leituras" que uma série fotográfica pode proporcionar ao pesquisador que a ela se dedique.

Procuramos encarar a fotografia como um documento, rico em informaçōes e significados, que nos coloca direto com um momento, um personagem e uma época.

Ao longo de sua história, a Fundação Oswaldo Cruz acumulou um acervo fotográfico significativo, tanto no que diz respeito ao conteúdo das informações contidas nas imagens, o que poderíamos associar a importância qualitativa dos fatos, quanto ao volume, implicando, aí, a diversidade temática.

Deste acervo, podemos destacar o excelente nível técnico das fotografias realizadas por J. Pinto, fotógrafo do Instituto Oswaldo Cruz, durante, aproximadamente, 40 anos.

A Casa de Oswaldo Cruz, inaugurada em 19 de janeiro de 1986, engloba, em sua proposta, vários projetos na área de memória e saúde, entre os quais o Projeto Iconográfico, que tem, como um dos seus objetivos, a recuperação do debate que envolve a fotografia como fonte histórica e como registro referencial, para pesquisas no campo das ciências biológicas, sociais, políticas e da saúde pública, além de contribuir para enriquecer abordagens sobre arquitetura do início do século, mentalidade, cultura, etc, uma vez que o universo captado pelas fotos do acervo do IOC, remonta às primeiras tentativas e experiências de Oswaldo Cruz, até os dias de hoje, abrangendo quase todas as atividades da instituição.

Numa primeira avaliação do acervo iconográfico, os documentalistas, Wanda Weltman e Fernando A. Pires Al- 
* Lissovsky, Mauricio. "A foto. grafia como documento histó. rico", in Fotografia; Ciclo de Palestras sobre fotografias. Rio de Janeiro, FUNARTE, 1983. p. 117.126 . ves, constataram a existência no arquivo permanente de caráter científico, do seguinte material:

a) negativos em vidro, em base flexível e em papel;

b) positivos em vidro (diapositivos), em base flexível (transparências) e em papel (fotografias).

Ao iniciar o trabalho de recuperação e preservação das fontes iconográficas, produzidas e acumuladas pela FIO. CRUZ, nos deparamos com uma nova problemática, a da leitura das informações contidas nas fotografias, indispensável tanto para o trabalho de organização do acervo (questão associada a classificação) quanto para o trabalho do pes. quisador, que utilizará estas informações como fonte para a recuperação histórica da trajetória da ciência, no Brasil, envolvendo temáticas, principalmente, relacionadas à saúde pública, a formação dos cientistas, as políticas de saúde da instituição, as prioridades estabelecidas pelo Estado, etc.

Para o pesquisador a leitura de qualquer fonte requer um trabalho de reflexão entre as fontes $e$ as hipóteses, $o$ que lhe permitirá estabelecer as "perguntas" que deseja fazer aos documentos. Esta relação fontes-hipóteses sugere a necessidade da "crítica interna" do documento. Nesta etapa, o pesquisador procurará, de acordo com as suas hipó. teses, indagar ao documento aquilo que ele não deseja revelar, priorizando as informações, ou as "pistas" contidas nas "entrelinhas" do mesmo, sem perder a perspectiva do contexto histórico e do momento cultural responsável, em parte, pela forma e pelo conteúdo assumido pelo documento.

Maurício Lissovsky é categórico ao afirmar que o pes. quisador não dispõe de um método que lhe permita prescin. dir da subjetividade da perspectiva do fotógrafo. Segundo ele, "no processo de produção da fotografia tem-se que combinar três elementos: conteúdo da imagem, o fotógra. fo e a tecnologia utilizada." Com relação ao conteúdo da foto, Lissovsky observa que, "a primeira coisa a mostrar em relação ao conteúdo da fotografia é o momento histórico que ela está retratando: fazer um movimento em direção ao contex to da imagem (. . .). Há outro tipo de movimento de aproximação de conteúdo, que é de comparação daquela fo. to que interessa com outras fotografias que tenham relação com ela."*

A utilização da imagem, animada ou não, tornou-se comum como forma de comprovar ou acrescentar informa. ções às nossas observações cotidianas. A TV, os jornais, as revistas, etc, diariamente, nos trazem, com uma incrível rapidez, conteúdos completados por imagens, e não raramente, as imagens assumem, em si, o conteúdo básico das infor. mações que nos são transmitidas.

Mesmo conscientes de que o processo tecnológico que envolve nossa sociedade é irreversível, a maioria dos histo- 
riadores vêem, cum algum preconceito e resistência, o uso da imagem como meio para respaldar ou construir suas hipóteses. Tal procedimento implica no entrave ao desenvolvimento teórico-metodológico indispensável para minimizar os riscos das generalizações ou das particularizaçōes possíveis, quando da utilização inadequada das fontes, sobretudo, das não convencionais.

Boris Kossoy buscou, em José Honório Rodrigues, uma observação bastante procedente para a questão da imagem, como fonte histórica: "A fotografia em si, o filme em si não representam, tanto quanto qualquer documento velho ou novo, uma prova de verdade. Toda a crítica externa e interna que a metodologia impõe ao manuscrito impõe, igualmente, ao filme. Todos podem, igualmente, ser 'montados', todos podem conter verdades e inverdades. Existe, naturalmente, para cada espéce de fonte, uma possibilida. de especial de falsificação, e conhecê-las é a tarefa de críticos de fontes."*

Vale reforçar que a preocupação com a utilização da fotografia como fonte histórica é recente, uma vez que, até há pouco tempo, a fotografia servia mais para ilustração (prova), ou seja, como forma de referendar uma afirmação textual. Sua função estava restrita ao papel de cristalizar a imagem de uma "verdade", jả confirmada e subsidiada pelos textos escritos.

Para o pesquisador, sobretudo, para o historiador a fotografia, talvez, represente a detecção de uma fração especial com inúmeros significados temporais.

Na visão poética de Susan Sontag, "este, possivelmente, é o seu exercício, pois só a fotografia transforma o pas. sado em objeto de carinhoso respeito, confundindo diferenças morais e desarmando julgamentos históricos, através do patético generalizado - que é o olhar para o tempo passado."*

Maurício Lissovsky ao sistematizar a reflexão sobre obje to e espaço muito contribui para o avanço metodológico da utilização da imagem como fonte histórica. "O sujeito, quando olha a fotografia, estabelece uma ponte entre aquele momento e o espaço que está na imagem e o momento que ele está vivendo. Como a distribuição dos objetos no espaço não é gratuita, tudo se posiciona no espaço, devendo serem levadas em consideração as relações entre us objetos. A orientação dos corpos também não é gratuita, eles traduzem orientações: linhas de autoridade, de subordinação, de hierarquia, de disciplina (. . .). A explicação espacial da cultura, da política, das relações sociais pode ser percebida".* Exemplificando:
* Kossoy, Boris. "A fotografia como fonte historica; introdução à pesquisa e interpreta. ção das imagens do passado. São Paulo, Museu da Ind. Com e Tecnologia de São Paulo - SICCT, 1980. p. 29.

*Sontag, Susan. Ensaios sobre a Fotografia. Ed. Arbor, RJ, 1983.

-Lissovsky, Mauricio. op. cit. p. 118. 
PESQUISA

Da esquerda para a direito sentados: Gomes de Farias, Carlos Chagas, não identificado,

Oswaldo Cruz, Adolfo Lutz, Cardoso Fontes, Parreiras Horta

Em pé: Arthur Neiva, Oscar Dutra e Silva, Gaspar Vianna, não identificado, Alcides Godoy

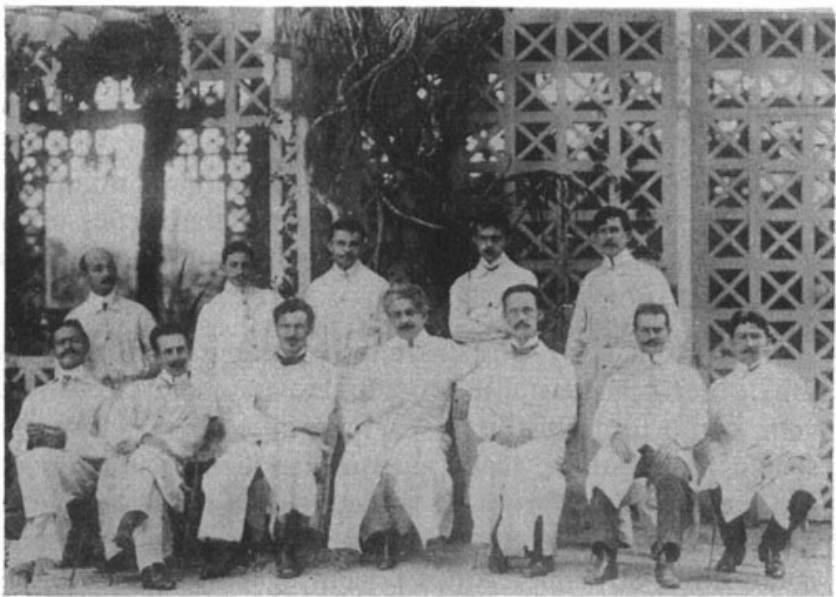

A observação das imagens remete o pesquisador a uma outra problemática, a da interpretação. Neste aspecto, Ivan Lima contribui para o debate do tema, "a fotografia como fonte", ao colocar com muita clareza que "a percepção visual é uma atividade puramente ótica: os olhos percebem as formas e as tonalidades dominantes, sem as identificar (. . .). A interpretação é uma ação mental permanente. É nesse estado que se manifesta o caráter polissêmico da foto. De uma forma geral, as pessoas fazem a mesma leitura, mas cada uma interpreta de sua forma, em função de sua idade, do seu sexo, da sua profissão, de sua ideologia, en-

* Lima, Ivan. "Linguagem fotográ. fica". op. cit. p. 59. fim, do seu saber"*, e em função de seu objeto de estudo.

Sugerimos, aqui, um exemplo dessa questão.

Apenas como exercício de reflexão, observamos algu. mas diferenças fundamentais no registro da problemática de duas doenças: febre amarela e doença de Chagas).

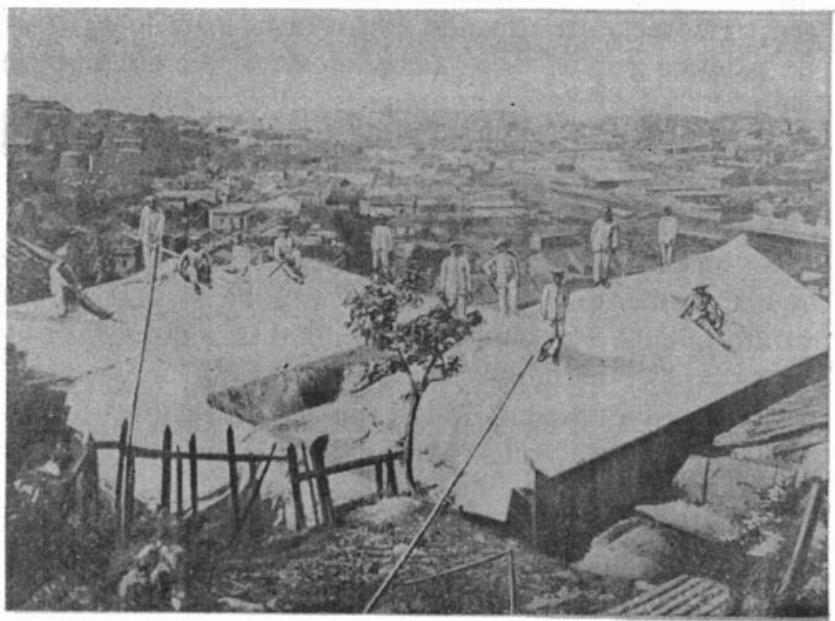

Serviço de Profilaxia da Febre Amarela. Preparaçäo das casas visando a destruiça dos mosquitos com vapor de enxofre.

Cadernos de Saúde Pública, R.J., 3 (3): 297-305, jul/set, 1987 
A primeira foto capta um "universo" mais ampliado e permite ao observador a associação da doença com o meio social, dando importância às medidas preventivas como meio essencial para a profilaxia da doença, permitindo, também, ao pesquisador, iniciado no tema, formular hipótese que possa vir a assumir tal relevância que leve a posterior investigação.

Tal hipótese poderia remeter o pesquisador à questão da evolução dos mecanismos científicos. Enquanto a ciência não dispunha de "meios eficazes" que possibilitassem um controle a curto prazo, a alternativa voltava-se para a questão do saneamento. $O$ que não está demonstrado na segunda foto. Nela, o sujeito aparece sob im fundo neutro, distanciado de seu meio social e da sua realidade econômica, a preocupação parece estar dirigida, apenas, para o registro da doença já pesquisada na época.

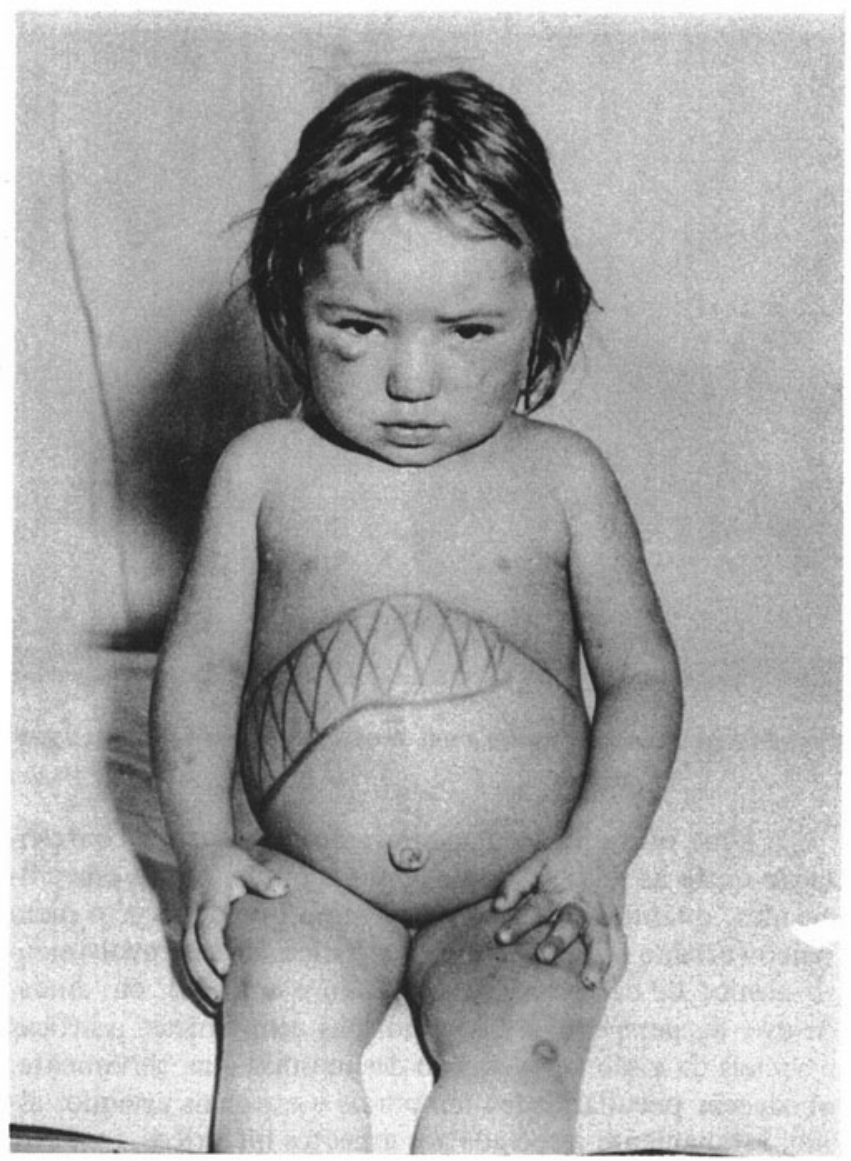

Cadernos de Saúde Pública, R.J., 3 (3): 297-305, jul/set, 1987 
Sugerindo que o cientista, no caso Carlos Chagas, tenha passado a preocupar-se a partir dos trabalhos desenvolvidos em Lassance, com a evolução da doença, isto é, do quadro clínico. As fotografias deixam de mostrar o indivíduo e seu ambiente, passando a registrar o paciente objeto e a evolução da doença. Chegando, inclusive, a desenhar, no corpo do sujeito, os contornos de órgãos aumentados para, dessa forma, melhor acompanhar a evolução da tripanossomíase americana. Cabe salientar que a pesquisa de Chagas revelou-se como modelo de medicina experimental no Brasil, estando talvez, aí, uma das explicações para a ênfase do registro clínico. Por outro lado, o pesquisador poderia abrir, a partir dessa informação, um novo interesse, o de investigar como, de que maneira e por que a Instituição passa a investir, verticalmente, na medicina experimental. Tal proposta encaminharia, talvez o estudo para as questōes relativas à ciência pura e aplicada e todas as demais implicações suscitadas, a partir desse objetivo.

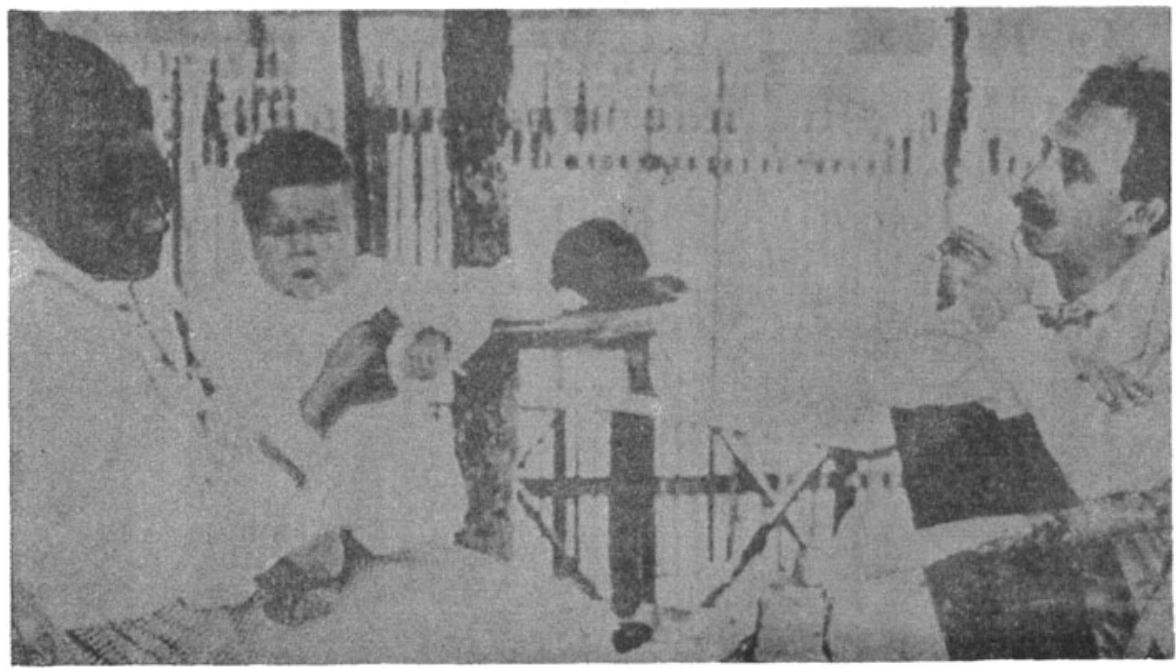

Carlos Chagas dando consulta a um doentinho em Lassance em 1908

Uma outra hipótese poderia dirigir-se para a confrontação entre as duas doenças, observando as devidas especificidades, quanto ao caráter epidêmico e endêmico, o meio físico (urbano e rural), as características do desenvolvimento clínico de cada uma delas (agudo e crônico), ou, ainda, dentro da perspectiva das condições econômicas, políticas e sociais da visão e concepção das mesmas que, certamente, obedecem peculiaridades temporais e espaciais estando, assim, intimamente associada aos aspectos históricos. 
No período Oswaldo Cruz e no início da gestão Carlos Chagas, no Instituto Oswaldo Cruz, as soluções encontradas para promover o controle das doenças dependiam, principalmente, da eliminação do vetor. Nesse momento, as imagens registradas mostram as casas, o meio social, o conjunto de pessoas. A partir do avanço das pesquisas, o registro prioriza os espaços sociais limitados, em função da ampliaçāo dos detalhes dos efeitos do "mal", sobre o indivíduo.

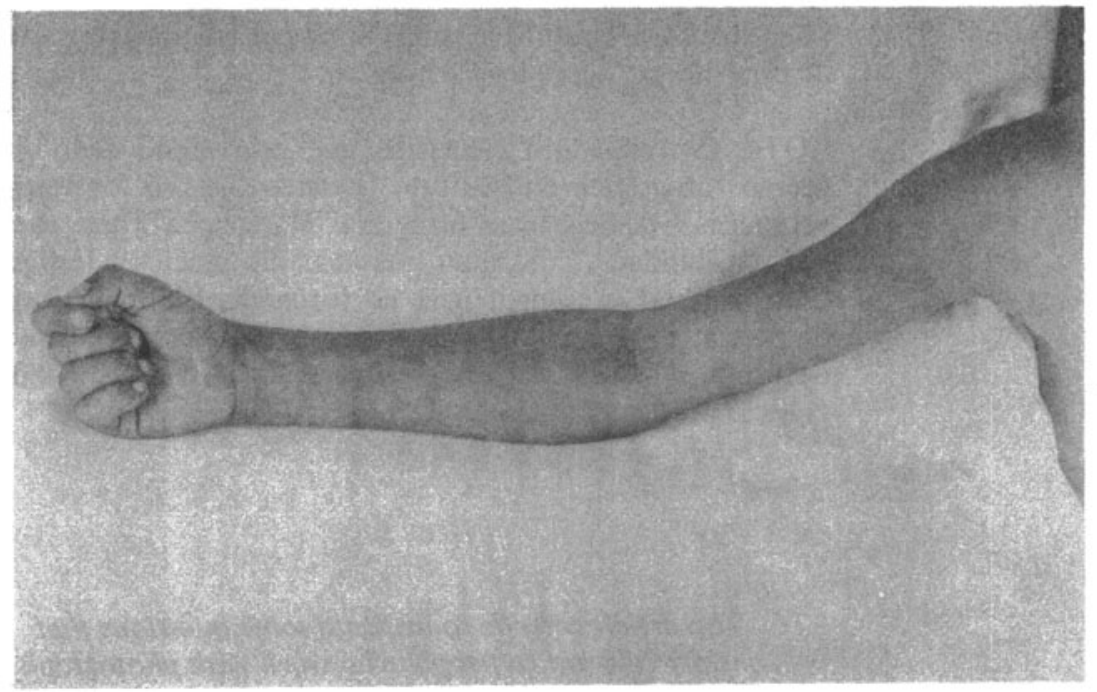

\section{Membro superior do Chagásico}

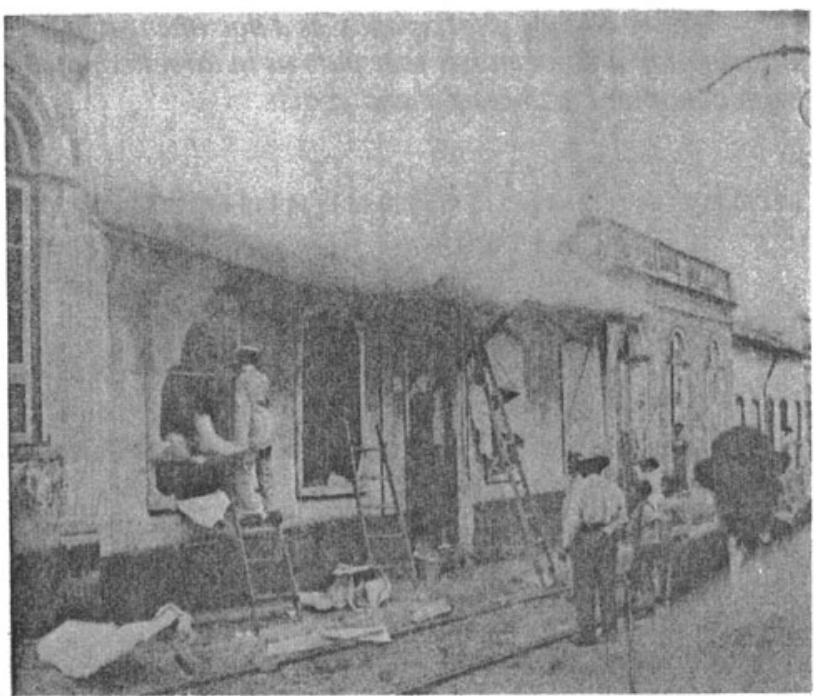

"Prolilaxia da Febre A marela

Obitos 1910

Foto J. J. Monteiro (Foto)

Cadernos de Saúde Pública, R.J., 3 (3): 297-305, jul/set, 1987 
Ricardo Holanda contribui para o desenvolvimento dessa reflexão observando que:

"Toda coleção de fotografias é um exercício interes. sante de montagem da história. Uma fotografia, no caso, é um objeto que possui status pelas coisas identificadas e achadas - como fragmentos de um mundo que já não existe. A reabilitação de velhas fotografias - quando se torna abstrato e aberto a qualquer tipo de interpretação."

Mais uma vez, deve-se salientar que essa leitura se propõe, apenas, a levantar algumas hipóteses, sem a pretensão de estabelecer "verdades" históricas.

NOTA: O tratamento científico que está sendo dado ao acervo fotográfico do Instituto Oswaldo Cruz só foi possível graças à dedicação da fotógrafa "Mariazinha"*que, com sua sensibilidade, conseguiu preservar tão preciosas fontes. Cabe lembrar a competência do fotógrafo Flávio Ribeiro de Souza, que vem colaborando para enriquecer o trabalho de produção, preservação e recuperação das fontes iconográficas produzidas pelo I.O.C.

This article intends to instigate some questions that we consider relevant to people who work with photography as a historical source of information.

Therefore it suggests various appreciation to searchers as it is usual when someone looks at a series of photos.

We try to face photography as a document rich on information and meanings that puts us in direct contact with a moment, a character and epoch.

1111111111111111111111111111111111111111111111111111111111

BIBLIOGRAFIA:

1. FUNARTE. "Fotografia. Ciclo de Palestras sobre fotografia": Rio de Janiro. 1983.

2. KOSSOY, Boris. A fotografia como fonte histórica; introdução à pesquisa e interpretaçāo das imagens do passado. São Paulo, Museu da Ind. Com. e Tecnologia de São Paulo - SICCT 1980.

3. SONTAG, Susan. Ensaios sobre Fotografia, Editora Arbor, Rio de Janeiro, 1983. 
4. FONSt:CA, Olympio Filho da. A Escola de Manguinhos; contribuiçāo para o estudo do desenvolvimento da medicina experimental no Brasil. Separata do tomo II de "Oswaldo Cruz monumento Histórico", SP, MCMLXXIV" 